\title{
O ESTÁGIO DE PESQUISA EM HISTÓRIA: RELATANDO A EXPERIÊNCIA DA DIGITALIZAÇÃO DE DOCUMENTOS OFICIAIS
}

\author{
RESEARCH INTERNSHIP IN HISTORY: REPORTING THE EXPERIENCE OF \\ SCANNING OFFICIAL DOCUMENTS
}

\section{LA PASANTÍA DE INVESTIGACIÓN EN HISTORIA: RELATANDO LA EXPERIENCIA DE LA DIGITALIZACIÓN DE DOCUMENTOS OFICIALES}

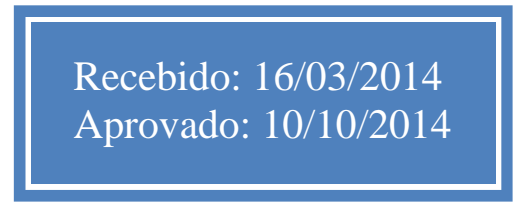

\author{
Clayton Cardoso Romano ${ }^{1}$ \\ Larissa Stephani Costa ${ }^{2}$ \\ Rochelle Gutierrez Bazaga ${ }^{3}$ \\ Thayane da Rocha Cruz Dias Freitas ${ }^{4}$ \\ Wagner da Silva Teixeira ${ }^{5}$
}

0 trabalho do historiador é dado principalmente pela análise de fontes que podem ser de diversos tipos, como jornais, revistas, relatos, livros, imagens e documentos oficiais. Esses documentos podem ser armazenados em arquivos públicos ou pessoais, no entanto, com o avanço da tecnologia vem se tornando comum encontrar fontes em meios virtuais. 0 presente trabalho tem por objetivo apresentar e discutir a importância do estágio na área de pesquisa em História e do manuseio de fontes históricas. No estágio realizado por duas alunas do curso de história da UFTM na Câmara Municipal de Uberaba no período de Outubro/2013 à Abril/2014, a digitalização dos livros de atas e veiculação digital desses documentos é uma das principais atividades. 0 estágio é orientado por dois professores do curso de História e supervisionado pela Diretora de Documentação e Pesquisa da Câmara. 0 artigo discuti a importância desse estágio, de caráter não obrigatório, para a formação acadêmica do historiador, sendo que esta atividade propicia o desenvolvimento de habilidades e competências adquiridas durante a formação, assim, desenvolve as práticas profissionais e capacita para atuar em diversas áreas do seu campo.

Descritores: Fontes de dados; Estágios; História.

The historian work is principally done with source analyze, and can be in different types like newspapers, magazines, reports, books, pictures and official documents. These documents can be lay in public or personal archive, however, with so many technological advances is common find this documents in virtual media. The goal of this work is to discuss the importance of work as a trainee in History`s research area and the handling with historical`s sources. In the stage, performed by two students from the history course of UFTM on Uberaba City Council, MG, Brazil, in the period October/2014 to April/2014, scanning books of Acts and transforming in digital documents was one of the main activities. The stage is driven by two professors of History Course and supervised by the Director of Documentation and Research Board. The article discussed the importance of this not mandatory stage for the academic training to futures historians. The stage enables the trainee to development of skills and competencies acquired during the graduation so, can develop the professional practices and enables the trainee to act in several areas linked with History.

Descriptors: Data sources; Internships; History.

El trabajo del historiador en su mayoría ocurre por el análisis de fuentes que pueden ser de diversos tipos, tales como periódicos, revistas, informes, libros, fotos y documentos oficiales. Estos documentos pueden ser almacenados en archivos públicos o particulares, sin embargo, con el avance de la tecnología es cada vez más común encontrar fuentes en medios virtuales. Este trabajo tiene como objetivo presentar y discutir la importancia de las pasantías en el campo de la investigación de la historia y el manejo de las fuentes históricas. En la pasantía de dos alumnas del curso de historia de la UFTM en la Cámara Municipal de Uberaba, MG, Brasil, entre los meses de octubre de 2013 hasta abril de 2014. El escaneo de los libros de actas y la transmisión digital de estos documentos es una de las principales actividades. La práctica es conducida por dos profesores del curso de Historia y supervisada por la Directora del Departamento Documentación e Investigación. El artículo discute la importancia de esta pasantía no obligatoria, para la formación académica de historiador. La práctica permite el desarrollo de habilidades y competencias adquiridas durante la formación, de este modo mejora el ejercicio profesional y permite actuar en diversas áreas de su campo.

Descriptores: Fuentes de datos; Pasantías; Historia.

${ }^{1}$ Doutor em História. Professor Adjunto do curso de História da Universidade Federal do Triângulo Mineiro (UFTM). claytonromano@yahoo.com.br

${ }^{2}$ Graduanda em História na UFTM. Estagiária na Câmara Municipal de Uberaba no Projeto Memória Viva. laristephani@gmail.com

${ }^{3}$ Historiadora. Diretora do Departamento de Documentação e Pesquisa da Câmara Municipal de Uberaba. Supervisora de estágio do Projeto Memória Viva. rochelle_gutierrez@hotmail.com

${ }^{4}$ Graduanda em História pela UFTM. Estagiária na Câmara Municipal de Uberaba no Projeto Memória Viva. rochathayane@gmail.com

${ }^{5}$ Doutor em História Social. Professor Adjunto e coordenador do curso de História da UFTM. wagnersteixeira@yahoo.com.br 


\section{INTRODUÇÃO}

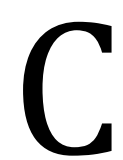
om a criação e organização da Escola dos Annales em 19291, vários conceitos e práticas historiográficas foram repensados e alargados. Dentre esses conceitos está o conceito de fonte histórica. 0 que é ou o que pode ser considerada fonte para o trabalho do historiador?

De acordo com Marc Bloch², tudo que o homem toca pode ser considerado um vestígio. Documentos como atas de reuniões de uma casa legislativa podem ser fontes históricas importantes, pois, por meio de questionamentos e da análise das reuniões oficiais, pode-se entender como uma sociedade se organiza politicamente ao longo do tempo.

As atas são registros tidos como oficiais, porém contêm o que determinada ordem política da época selecionou ou escolheu. As atas da Câmara Municipal de Uberaba, assim como todas as fontes dos historiadores - cartas, cadernos, livros, entre outros, são construções do homem em seu tempo. Ao analisar cada fonte histórica, deve-se levar em consideração o contexto, o lugar, o objetivo da criação de tal fonte e seu autor, e de quem a analisa, portanto, apesar das atas serem consideradas fontes "oficiais" a sua importância como fonte histórica irá depender dessas variáveis. "Assim, para o historiador, o documento atinge valor pela teia social que o envolve e pelo que revela de mais amplo de uma época e de uma sociedade ${ }^{3}$.

Como a importância da fonte não depende somente de um profissional, o trabalho do historiador consiste também em tornar fontes como essas acessíveis ao trabalho e a interpretação de outros pesquisadores.

O Projeto Memória Viva realiza um trabalho que consiste em deixar fontes históricas mais acessíveis a todos. Este é um projeto de estágio extracurricular realizado no Departamento de Documentação e Pesquisa da Câmara Municipal de Uberaba por duas alunas, uma do $5^{\circ}$ e outra do 7음 período do curso de História da Universidade
Federal do Triângulo Mineiro (UFTM) sob a orientação de dois Professores do curso de História e supervisionado pela Diretora do Departamento.

Para as estagiárias é de extrema relevância realizar esse exercício de trabalhar com fontes documentais durante a graduação, pois o conjunto da teoria, prática e experiência que hoje se beneficiam, facilitará o manuseio e a visão histórica para trabalhar em qualquer área de atuação do historiador. Assim, o presente trabalho tem por objetivo apresentar e discutir a importância do estágio na área de pesquisa em História e do manuseio de fontes históricas.

\section{MÉTODO}

0 artigo trata de um relato de experiência do estágio realizado na Câmara Municipal de Uberaba no Departamento de Documentação e Pesquisa com carga horário de 20 horas semanais. 0 estágio tem o período máximo de realização de dois anos para cada aluno e, depois de encerrado esse período é realizado uma nova seleção.

Para a realização do trabalho de digitalização das atas das reuniões legislativas do século XIX ao XX são utilizados os seguintes instrumentos: luvas, máscaras e pinceis para não danificar as fontes; aparelho de scanner dobrável, computador e, para o armazenamento dos dados HD de 1 Terabyte.

Cada ata contém cerca de 400 páginas, digitalizadas uma a uma e posteriormente alocadas em um servidor da Internet online e no seguinte endereço eletrônico:

http://www.camarauberaba.mg.gov.br/me moriaviva/atas.aspx ${ }^{4}$.

0 presente trabalho se refere às atividades desenvolvidas no período de Outubro e 2013 à Abril de 2014.

\section{RESULTADOS}

0 trabalho oferece às estagiárias a experiência de entrar em contato direto com as fontes, o que por vezes pode ser difícil para o historiador devido algumas 
barreiras, como a distância ou custos com pesquisa de campo. 0 principal resultado do trabalho é a possibilidade de proporcionar facilidade e acessibilidade para o trabalho de pesquisa em história, não sendo necessário que o pesquisador viaje ou se desloque até o local/arquivo onde estão os livros de atas.

Ao tornar a fonte de fácil acesso ao pesquisador é possível que historiadores de outros estados ou cidades possam estudar a História de Uberaba e/ou do poder legislativo dessa região. Outro ponto positivo é a preservação do documento original, pois digitalizando as atas o número de consultas manuais é reduzido, o que diminui os desgastes das páginas dos livros e possíveis acidentes durante consultas. Importante ressaltar, que esse trabalho foi feito de forma que não prejudicasse ou danificasse o documento. Para isso são utilizadas luvas apropriadas para o manuseio das atas, deslocamento e armazenamento das mesmas em local adequado.

0 estágio pode ser realizado em qualquer período do curso por ser de caráter não obrigatório. Para o interessado em fazer o estágio é aberto um edital para seleção de dois alunos para realizar o trabalho. 0 processo de seleção tem três etapas: prova escrita com tema sorteado, entrevista e análise curricular. 0 primeiro e o segundo colocado são os primeiros a assumirem o estágio, se caso um dos dois deixe o estágio antes do tempo limite de dois anos, os outros alunos a partir da terceira posição do processo seletivo são convocados.

O Projeto Memória Viva foi criado no ano de 2010 por meio de um convênio e apoio firmado entre a Câmara Municipal de Uberaba e o curso de História da UFTM oferecendo oportunidade de pesquisa para graduandos do referido curso. 0 tempo do estágio é de no máximo dois anos, no entanto, o presente trabalho se refere ao período das atividades desenvolvidas entre Outubro de 2013 à Abril de 2014.

Entre os trabalhos está a digitalização de atas e outros documentos como fotos, a montagem e gravação de vinhetas de 1 minuto para a TV Câmara intituladas História em 1 minuto, apresentação de artigos e trabalhos sobre a História da Câmara e a cidade de Uberaba. Nesse artigo, no entanto, o foco é o trabalho com as fontes oficiais.

Historiadores em formação aprendem durante a graduação teorias relacionadas ao uso de fontes, porém, a prática é necessária e muitas vezes faz falta. 0 programa de estágio possibilita colocar em prática, ainda em formação todos esses conhecimentos.

No estágio do Projeto Memória Viva, além de colocar em ação algumas teorias entra-se em contato com o objeto de trabalho do pesquisador, as fontes. Sejam elas documentais (Atas), ou até mesmo orais de pessoas que há tempos trabalham ou já trabalharam na Câmara. Essas fontes são levadas próximo à população, para que aprendam, conheçam e pesquisem a história de Uberaba. Dessa forma, o estágio possibilita a aprimorar o conhecimento em pesquisa e refletir sobre o papel do historiador como sujeito histórico na sociedade.

\section{DISCUSSÃO}

Analisar e interrogar os vestígios deixados pelo homem no tempo é uma prática alcançada após a criação da Escola dos Annales, de 19291. March Bloch pertencente a essa geração apresenta um ofício de investigação de fontes históricas, e nesta se inclui dentre tantas: cartas, jornais, fotografias, esculturas, pinturas, fotos, livros e documentos 2,5 . Todas elas foram construídas por alguém com algum objetivo, aparente ou não, portanto devem ser trabalhadas de forma cautelosa, construindo o fato, ou período, em seus diversos aspectos, tendo assim, diferentes visões e versões desse.

Os fatos podem ser interpretados de formas diferentes, segundo cada historiador, isto porque a construção e interpretação das fontes dependem do conhecimento, da formação, das referências e objetivos de cada profissional, porém este sempre busca recriar o fato o mais próximo possível, do que imagina ser o real.

REFACS (online) 2015; 3(1):40-45. 
Com o avanço da tecnologia desde o século XVIII, pensa-se em meios de comunicação e transportes mais rápidos e eficientes que cheguem ao maior número de pessoas e lugares. A informação atualmente viaja quilômetros em segundos devido às ferramentas de comunicação como a televisão, mas principalmente a Internet. Pensando nessa necessidade de comunicação do homem, foi criada a partir da década de 1930 a técnica da microfilmagem por meio da fotografia. Essa técnica foi pioneira para a salvação e preservação de documentos no formato digital, hoje a técnica mais utilizada é a digitalização ${ }^{6}$.

A lei $\mathrm{n}^{0} 5.433$, de 8 de maio de $1968^{7}$ regulamenta a microfilmagem de documentos no Brasil. De acordo com o Art. 2o, "Os documentos de valor histórico não deverão ser eliminados, podendo ser arquivados em local diverso da repartição detentora dos mesmos." Essa lei é importante para que os documentos considerados de valor para pesquisa histórica não sejam descartados. A regulamentação da técnica da microfilmagem possibilita nesse aspecto, a redução de grandes arquivos e contribui para manutenção e o aumento de acervos históricos no Brasil.

A atividade de digitalização permite a durabilidade do documento evitando o contato do homem com o papel, por exemplo, pode-se diminuir o seu desgaste ou possíveis acidentes que o danifique. Outros fatores podem influenciar na perda do documento como armazenagem incorreta, umidade, iluminação, temperatura, fungos e bactérias ${ }^{8}$ logo, se vários pesquisadores precisam de uma mesma fonte não é necessário que todos a manuseiem, podem consulta-la no formato digital.

Além disso, ao digitalizar e disponibilizar documentos históricos via Internet o pesquisador torna a fonte um material livre, da qual diversos pesquisadores podem consultar sem exigências burocráticas ou outros tipos de contratempos. Além disso, a fonte se torna "democrática", ou seja, não só historiadores têm acesso a ela, mas pesquisadores de outras áreas ou cidadãos que tem o interesse de estudar a história da própria cidade ou sociedade em que vive.

Se apropriar de tais tecnologias permite ao historiador aprimorar e promover seu trabalho. Documentos oficiais, relatos, gravações, imagens podem ser encontradas digitalizadas, ou em outros formatos, em sites e bancos de dados na Internet disponível para o estudo de pesquisadores do todo mundo. 0 contato do historiador com novas ferramentas de comunicação mostra como esse profissional se mantém atualizado ao uso de tecnologias da informática a favor do seu trabalho, o que quebra a ideia do historiador como alguém antiquado que vive em porões empoeirados analisando folhas de papéis amarelados.

No entanto, como aponta Almeida ${ }^{9}$ a utilização de fontes digitais ainda não está bastante difundida, devido a falta de regras e metodologias para o seu uso o que pode causar receio por parte de alguns historiadores. Ainda de acordo com o autor, a formulação de normas só será possível conforme essas fontes forem utilizadas ${ }^{9}$. $\mathrm{Ou}$ seja, o trabalho de digitalização contribui para a promoção e para a elaboração de métodos do seu uso.

0 fácil acesso aos documentos oficiais como as Atas do poder legislativo está diretamente ligado à formação e consolidação de uma memória coletiva a respeito da formação política e cultural de uma determinada sociedade, portanto, há necessidade de o homem "entender sobre sua existência e relações passadas para a construção de uma nova realidade ${ }^{8 " .}$

A prática de digitalização de documentos históricos no Brasil é realizada em diversos estados em diferentes instituições e áreas do conhecimento além da História como: Biblioteconomia, e Arquivologia. Alguns dos principais acervos com esse tipo de trabalho são os da Biblioteca Nacional, Biblioteca Nacional do Museu Digital, Domínio Público, Arquivo de Estado de São Paulo e a Biblioteca Nacional de Portugal ${ }^{10}$. 
Outros trabalhos também são realizados nessa área em outras instituições, como: o trabalho de estudantes da Universidade Federal de Pernambuco, por exemplo, que foi direcionado para a digitalização dos documentos referentes à Oficina Guaianases de Gravura, "um importante movimento artístico pernambucano que durou de 1974 a 1995, e cujo acervo atualmente se encontra sob a responsabilidade do Departamento de Teoria da Arte da UFPE11".

\section{CONCLUSÃO}

0 estágio propicia o desenvolvimento de habilidades e competências adquiridas durante a formação, assim, salientando a bagagem do estagiário com amplas práticas profissionais, capaz de atuar livremente em diversas áreas do seu conhecimento. Durante esse projeto o estagiário aprende, entre outras atividades, a manusear corretamente um documento oficial, o uso de luvas, o local de armazenamento e atenção ao manejar as atas que são fundamentais para a melhor conservação das mesmas.

Durante quatro horas por dia, através das fontes históricas da Câmara Municipal de Uberaba, que ali estão disponíveis, o estagiário de história revive a memória política, social e cultural da sociedade de Uberaba e ainda compartilha essas informações para que atendam a todos aqueles que buscam conhecer, reviver ou pesquisar e trabalhar o passado político da cidade. Isto é importante, pois, a ferramenta da internet aproxima o pesquisador de sua fonte, independente do lugar onde ele esteja ou do objetivo da pesquisa.

A disponibilidade de informações no site do Projeto Memória Viva não se restringe as Atas de reuniões da Câmara, mas também histórias de vereadores, notícias que circulavam nos periódicos da época, entre outros. E tudo isso faz com que, sem distinção, qualquer pessoa tenha o livre acesso ao passado político da cidade.

Tal estágio faz perceber a importância do papel de historiador, sendo que o resgate e construção de uma história que muita vezes foi esquecida e perdida pela população faz compreender a sua vivência no presente. Os costumes, a cultura, a individualidade de cada sociedade é examinada pelo historiador através de seu objeto de trabalho. As fontes são muitas, mas todas falam cada uma de um jeito e, contam histórias diferentes, e que uma vez contadas, tornam os vestígios e a memória dos uberabenses.

Esse trabalho pode contribuir para o estudo da arte e cultura regional como a importância desses movimentos para formação de determinadas sociedades, fornecendo fontes importantes para o trabalho do historiador.

\section{REFERÊNCIAS}

1. Burke P. A Escrita da História: novas perspectivas. São Paulo: Unesp, 1992. 354 p.

2. Bloch M. Apologia da História ou o ofício de historiador. Rio de Janeiro: Jorge Zahar, 2001. 139 p.

3. Karnal L, Tatsch FG. A memória evanescente. In: Pinsky CB, Luca TR. (orgs.) 0 historiador e suas fontes. São Paulo: Contexto, 2009. p. 09-27.

4. Câmara Municipal de Uberaba. Projeto Memória Viva [Internet]. Uberaba, MG: CMU; 2011 [acesso em 17 abr 2014]. Disponível em: http://www.camarauberaba.mg.gov.br/me moriaviva.

5. Reis JC. Escola dos Annales: a inovação em história. São Paulo: Paz e Terra; 2000. 200p. 6. Silva GP. A importância dos acervos digitais. Rev Bras ARC [Internet]. 2011 [acesso em 7 maio 2014]; 3(Ed Esp). Disponível em: http://www.restaurabr.org/siterestaurabr /ARC_Vol_3/A\%20IMPORTANCIA\%20DOS $\% 20$ ACERVOS\%20DIGITAIS\%20giseane $\%$ 20pescador.pdf.

7. Presidência da República (Brasil). Lei $\mathrm{n}^{0}$ 5433, de 8 de maio de 1968. Regula a microfilmagem de documentos oficiais e dá outras providências. D.O.U. [Internet], 10 maio 1968 [citado em 7 maio 2014]. Disponível 
http://www.planalto.gov.br/ccivil_03/leis/L 5433.htm.

8. Vieira LCB. Digitalização de documentos históricos: uma alternativa para a preservação e disseminação da memória e patrimônio cultural. In: Anais do 14.0 Encontro Regional de Estudantes de Biblioteconomia, Documentação, Ciência da Informação e Gestão da Informação [Internet]; 16-22 jan 2011; São Luís. São Luís: UFMA; 2011 [acesso em 5 maio 2014]. Disponível em: http://rabci.org/rabci/sites/default/files/ DIGITALIZA\%C3\%87\%C3\%830\%20DE\%2 0DOCUMENTOS\%20HIST\%C3\%93RICOS\% 20uma\%20alternativa\%20para $\% 20 \mathrm{a} \% 20$ preserva $\%$ C3\%A7\%C3\%A3o\%20e\%20dis semina\%C3\%A7\%C3\%A3o\%20da\%20me m\%C3\%B3ria\%20e\%20patrim\%C3\%B4ni o\%20cultural.pdf .

9. Almeida FC. O historiador e as fontes digitais: uma visão acerca da internet como fonte primária para pesquisas históricas. AEDOS: Rev Corpo Discente PPG Hist UFRGS [Internet]. 2011 [acesso em 5 maio 2014]; 3(8). Disponível em: http://seer.ufrgs.br/index.php/aedos/artic le/view/16776/11939.
10. Laboratório de Ensino de História do Recôncavo da Bahia. Fontes digitalizadas [Internet]. Cachoeira, BA: LEHRB; 2014 [acesso em 6 maio 2014]. Disponível em: http://www.ufrb.edu.br/lehrb/sites-apoioao-professor/objetos-digitais-ensinohistoria/fontes-digitalizadas/.

11. Santos ALF, Cintra I, Silva NB. Experiência na digitalização dos documentos históricos da oficina Guaianases de gravura. In: Anais do 33. Encontro Nacional de Estudantes de Biblioteconomia, Documentação, Gestão, e Ciência da Informação [Internet]; 18-24 jul 2010; João Pessoa. João Pessoa: UFPA; 2010 [acesso em 5 maio 2014]. Disponível em:

http://dci.ccsa.ufpb.br/enebd/index.php/e nebd/article/viewFile/89/41.

\section{CONTRIBUIÇÕES}

Clayton Cardoso Romano, Larissa Stephani Costa, Rochelle Gutierrez Bazaga, Thayane da Rocha Cruz Dias Freitas e Wagner da Silva Teixeira tiveram iguais contribuições na confecção do referido artigo. 